\title{
Justificación antropológica de los valores médicos
}

José Ramón Ayllón Vega

Filósofo y escritor

\section{JUSTIFICACIONES POSIBLES}

Los valores en general, y los valores médicos en particular, solo se pueden fundamentar en la base y la raíz de las acciones humanas. Esta base y raíz es precisamente la naturaleza humana.

Tal afirmación es casi de perogrullo, pero sucede que nuestra naturaleza, siendo una realidad objetiva, es tan compleja que da origen a interpretaciones subjetivas muy dispares.

Nadie puede negar que somos animales racionales, habladores, libres, sociales, sentimentales... Pero la interpretación de esos datos ciertos es incierta, múltiple y contradictoria, pues da lugar al realismo de Aristóteles y al idealismo de Platón, al racionalismo de Descartes y al irracionalismo de Nietzsche, al positivismo de Comte y al vitalismo de Ortega, al existencialismo de Sartre y al personalismo de Mounier...

Por fortuna, en última instancia, todas las posibles lecturas de la naturaleza humana se pueden reducir a dos, en directa correspondencia con las dos formas últimas de entendernos a nosotros mismos: el materialismo y la trascendencia.

\section{TRASCENDENCIA Y MATERIALISMO}

El materialismo piensa que el ser humano es, como escribe Borges:

Uñas, carne, sudor, vísceras, dientes.

Y su destino, según leemos en otro célebre verso de Quevedo, es acabar

En tierra, en polvo, en humo, en sombra, en nada.

Muy al contrario, desde la apertura a la trascendencia se puede ve al hombre como primo del mono, pero además y sobre todo, como criatura divina.
Ambas posibilidades fundamentan, de forma muy diferente, valores médicos esenciales, entre los que destaco el respeto a la vida, la compasión y la responsabilidad. Desde un pensamiento materialista, la última instancia fundante de la práctica médica es la legislación. En cambio, para la trascendencia, las leyes humanas deben reflejar, explicitar y respetar otras leyes más altas, escritas en la Naturaleza por su propio Autor.

La diferencia entre ambas posiciones es la diferencia entre Antígona y Creonte, entre Enrique VIII y Tomás Moro, entre Sophie Scholl y su interrogador nazi, entre Gandhi y sus jueces británicos. Una diferencia que puede resumirse en dos palabras, Leyes o conciencia, y que refleja una distinción de máxima relevancia: las leyes cambian, la conciencia no.

Esta visión no es relativa al etnocentrismo occidental, como a veces se oye, sino a la condición humana en toda su extensión. Por eso, Confucio, padre de la cultura oriental, piensa lo mismo que Occidente y lo expresa con esta magnífica formulación: "Si no se respeta lo Sagrado, no hay nada sobre lo que podamos edificar una conducta".

Los dos fundamentos mencionados -el trascendente y el materialista- implican dos formas muy diferentes de responsabilidad. La mera responsabilidad civil es siempre limitada -intramundana-, y puede ser arbitraria. Frente a ella, Gandhi resume su postura en estas palabras, dirigidas al juez: "Si existe un Dios por encima de nosotros, los ingleses tendrán que responder ante Él de lo que han hecho en la India".

La responsabilidad es, en cierto modo, el precio que hemos de pagar por nuestros actos libres, la obligación de justificar nuestras acciones en la medida en que afectan a los demás, en la medida en que "salpican". 
Ser responsable significa tener que responder de algo ante alguien. Desde Homero, ese alguien se escribe con mayúscula y está muy bien identificado. En la Odisea -esa conquista cultural sin la cual no existiría el primer mundo- se nos repite el deber de la hospitalidad, porque todos los huéspedes y mendigos son protegidos de Zeus. Cuatro siglos más tarde, cuando el sofista Protágoras afirmó que el hombre es la medida de todas las cosas, Sócrates y Platón puntualizaron que el hombre está, a su vez, medido por Dios. De hecho, solo sentirse responsable ante el Gran Testigo Invisible es lo que pone al ser humano en la ineludible tesitura de colmar un sentido concreto y personal para su vida, y de ver que su existencia tiene un valor absoluto e incondicionado.

En esta misma línea, tal vez la reflexión más famosa sobre la responsabilidad última del hombre la escribe Shakespeare. Se trata del soliloquio en el que Hamlet rechaza la posibilidad del suicidio -ser o no ser-"por el temor de un algo después de la muerte, esa ignorada región cuyos confines no vuelve a traspasar viajero alguno. Temor que confunde nuestra voluntad y nos impulsa a soportar aquellos males que nos afligen, antes que lanzarnos a otros que desconocemos".

\section{¿ES POSIBLE UN ACUERDO?}

¿Puede haber acuerdo entre trascendencia y materialismo? ¿Pueden coincidir ambas argumentaciones? Veamos el caso concreto del respeto a la vida. Para gran parte de la humanidad, dicho respeto deriva directamente del más escueto mandamiento bíblico: No matarás. Pero la defensa de la vida humana no es monopolio de la Biblia, pues se presenta a lo largo de la Historia como exigencia estrictamente racional, natural. Desde su agnosticismo, Umberto
Eco expresaba así su opinión sobre el respeto al embrión humano:

Tal vez estemos condenados a saber únicamente que tiene lugar un proceso cuyo resultado final es el milagro del recién nacido, y que decidir hasta qué momento se tiene derecho a intervenir en ese proceso, y a partir de cuál ya no es lícito hacerlo, no puede ser ni aclarado ni discutido.

Norberto Bobbio, uno de los máximos representantes del laicismo italiano, justificaba su oposición al aborto en estos términos: "No quiero dejar a los católicos el privilegio de defender la vida".

El acuerdo entre materialismo y trascendencia es posible en teoría, pero es muy difícil en la práctica. Para mostrarlo, volvamos a Grecia. Cuando Ulises regresa de Troya a Ítaca -aquella isla "hermosa al atardecer"-, se presenta disfrazado ante su porquero Eumeo, con aspecto de anciano harapiento. Eumeo no le reconoce, pero se compadece y le acoge con hospitalidad. Ulises lo agradece de veras, y el porquero le explica que no tiene importancia, que "no es santo deshonrar a un extraño, ni aunque viniera uno más miserable que tú, pues todos los forasteros y mendigos son de Zeus". Desde Homero, la referencia a la Divinidad se ve como indispensable para dotar al hombre de inviolabilidad. La Biblia, más explícita que Homero y Confucio, define al hombre como hijo de Dios, y sabemos que cualquier otra definición rebaja peligrosamente su dignidad. Si ser considerado hijo de Dios no siempre ha sido suficiente para proteger al hombre, ser mero animal racional o animal social es dar demasiadas facilidades para pisotearlo. Lo hemos comprobado más que nunca en el siglo XX, pues hemos sido capaces de inventar la música de cámara y la cámara de gas. 